\title{
> Elogio ao Mistério: revelações de atelier
}

> Ode to Mistery: revelations from the studio

\section{por Letícia Lopes}

Letícia Lopes nasceu em Campo Bom/RS em 1988. É Bacharel em Artes Visuais pelo Instituto de Artes da UFRGS (2015). Participou de várias exposições coletivas, destacando-se Caixa Preta (Fundação Iberê Camargo - 2018) e Lento Crepúsculo (Pinacoteca Ruben Berta - 2018). Em 2016 foi selecionada pelo Programa RS Contemporâneo, realizando a individual Presença Sinistra (Santander Cultural/RS). Em 2014 foi premiada na $3^{\circ}$ edição do Prêmio IEAVI (RS) e em 2019 foi indicada ao Prêmio PIPA. E em 2019 foi vencedora do $3^{\circ}$ Prêmio Aliança Francesa de Arte Contemporânea. E-mail: learaislopes@gmail.com.

ORCID: 0000-0002-1266-4387 


\section{Sobre o Ensaio Visual}

O presente ensaio propõe uma reflexão acerca dos limites, do poder e da natureza da linguagem representativa, confrontando-a com a lógica dos sistemas de crença e sugerindo aproximações e cruzamentos entre as noções de imagem (linguagem), aparição (superstição) e construção (representação). 


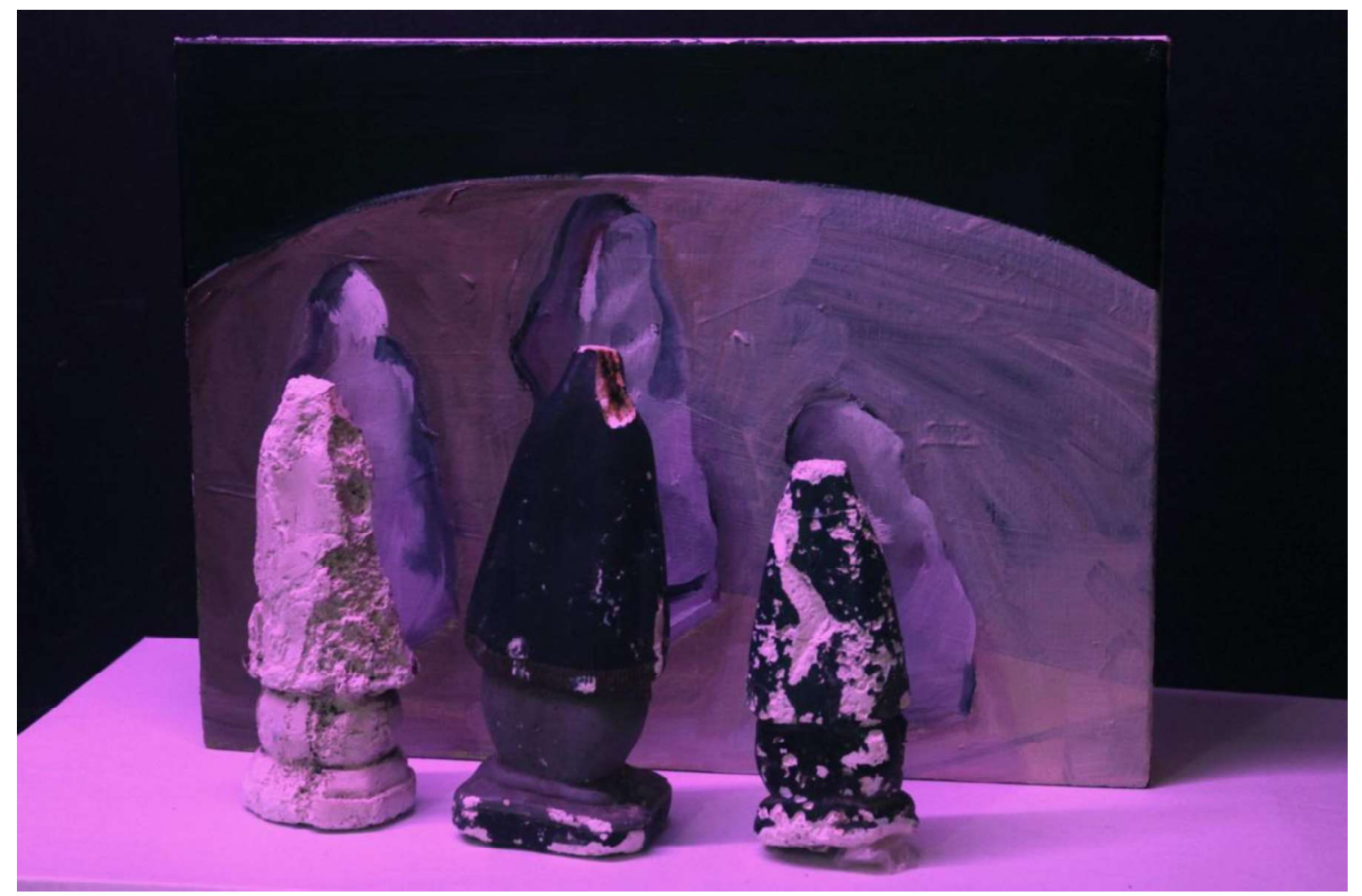

Revista PHILIA | Filosofia, Literatura \& Arte 

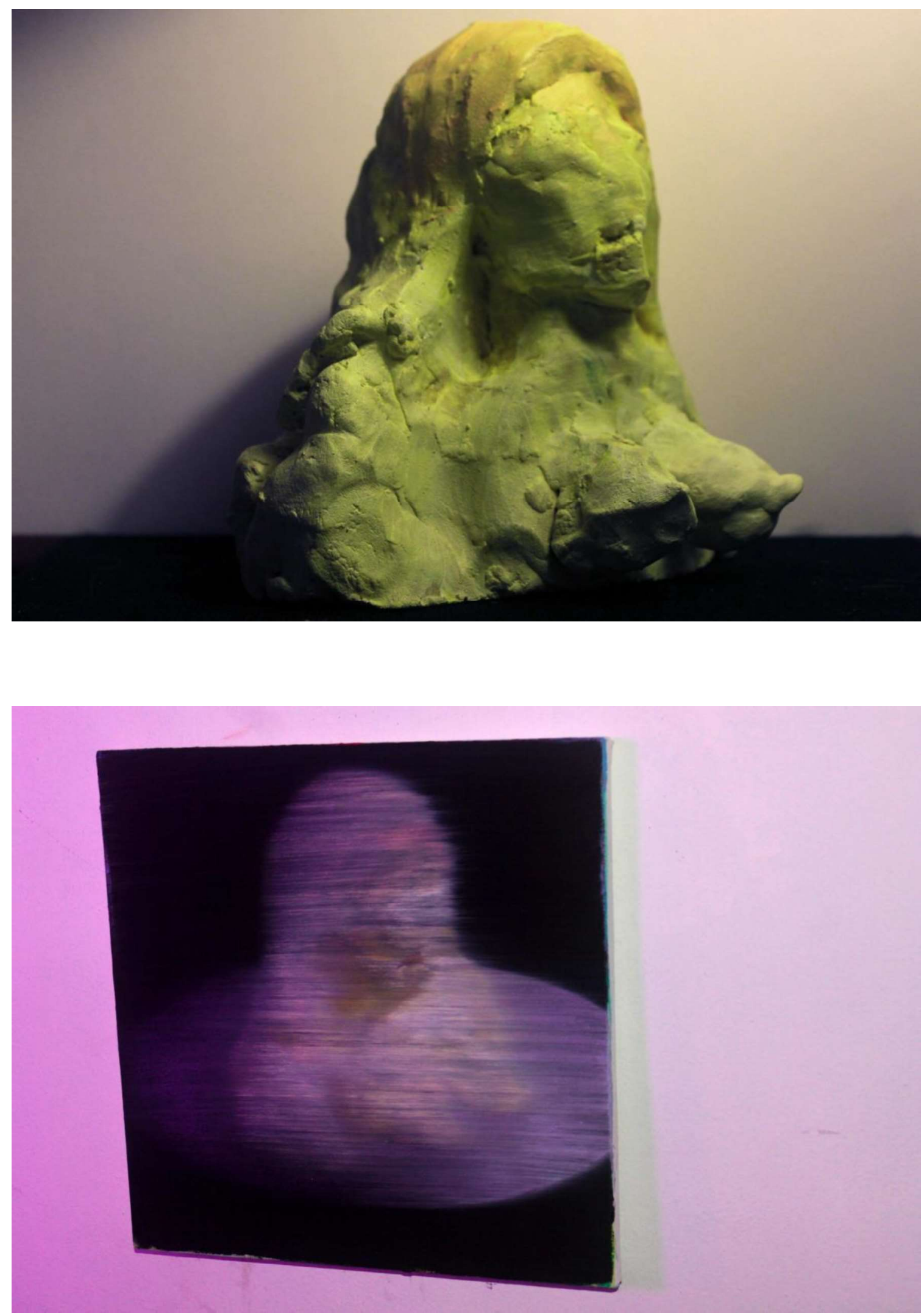

Revista PHILIA | Filosofia, Literatura \& Arte vol. $1, n^{\circ} 2$, outubro de 2019 ISSN 2596-0911 


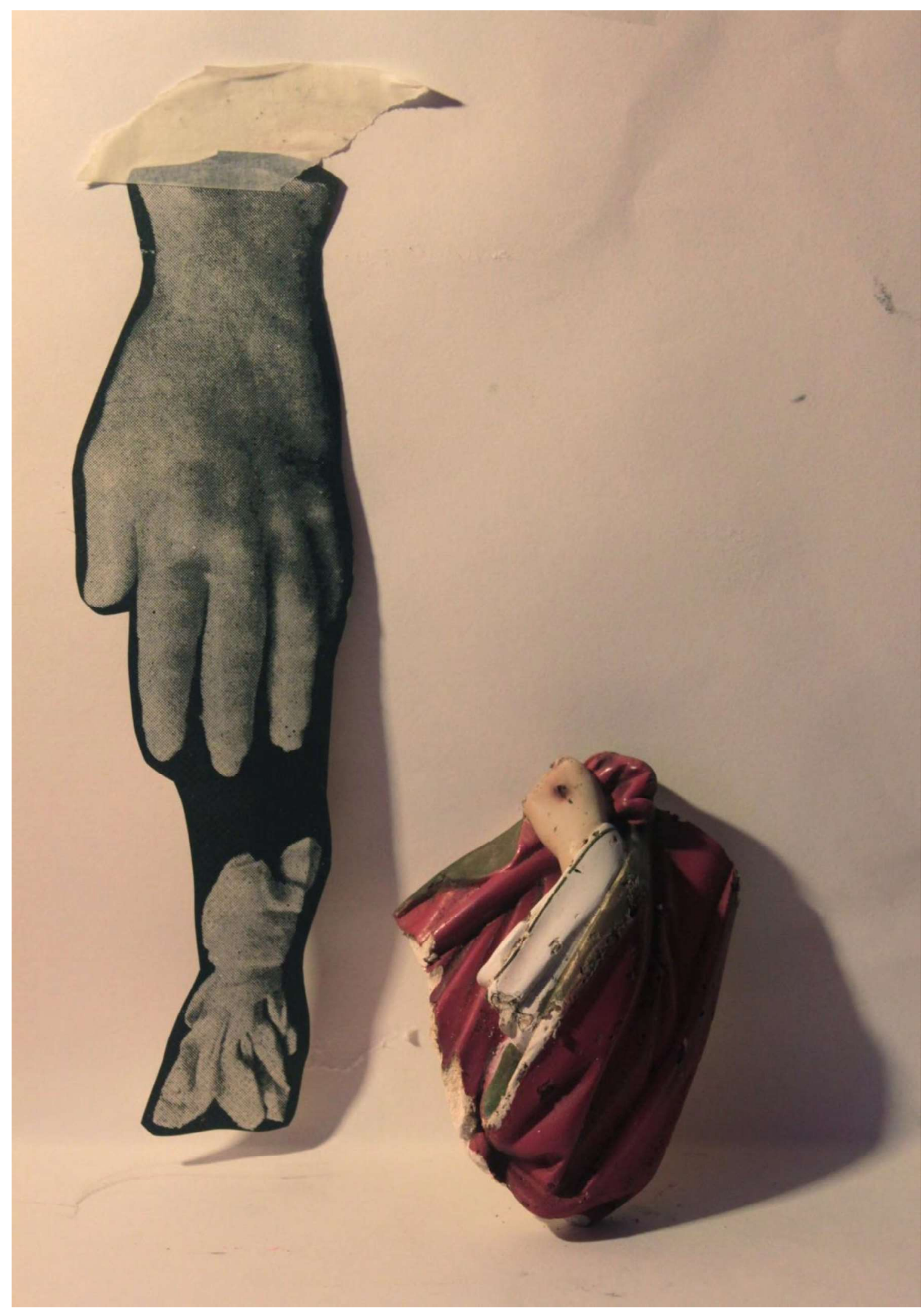

Revista PHILIA | Filosofia, Literatura \& Arte vol. $1, n^{\circ} 2$, outubro de 2019 ISSN 2596-0911 


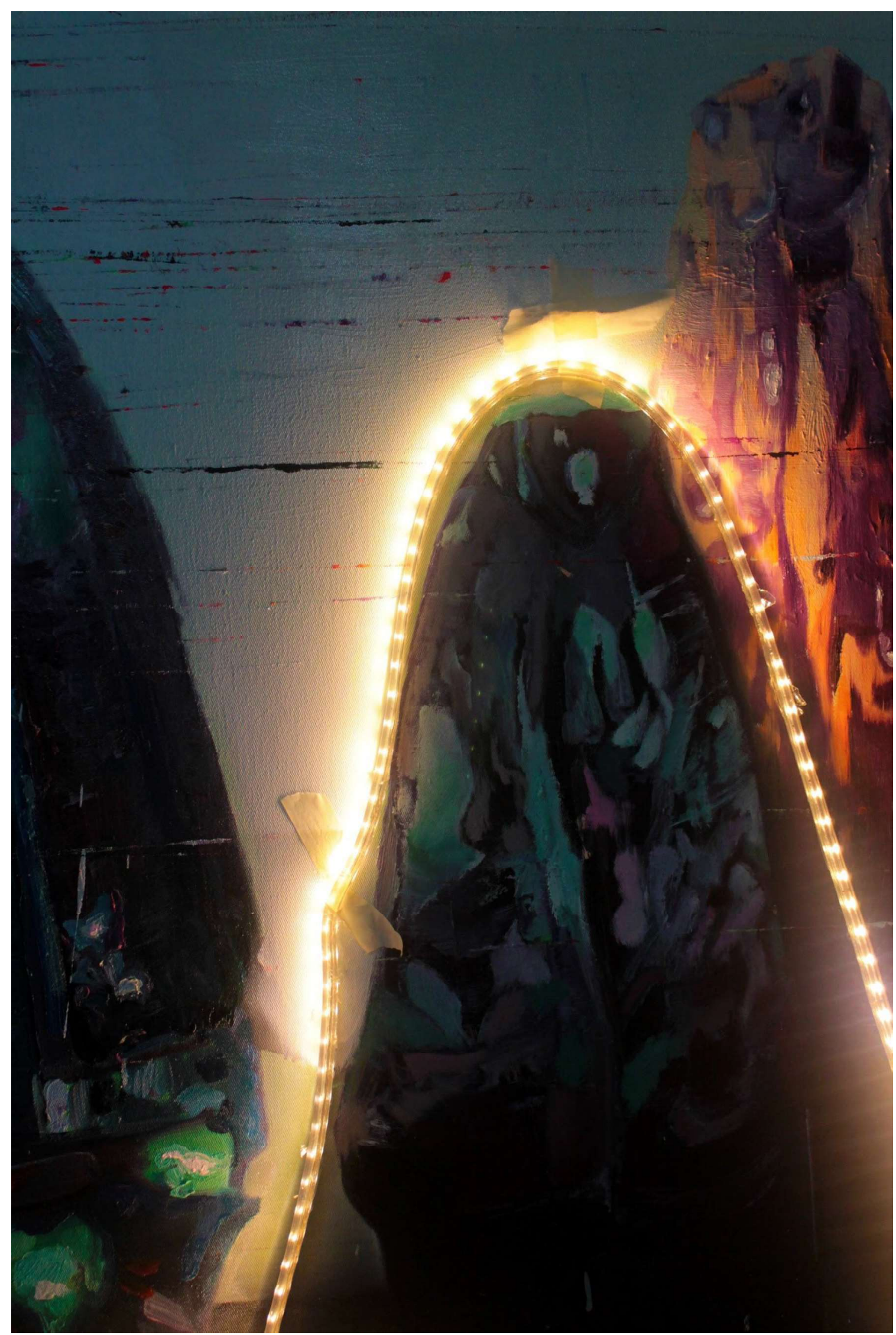



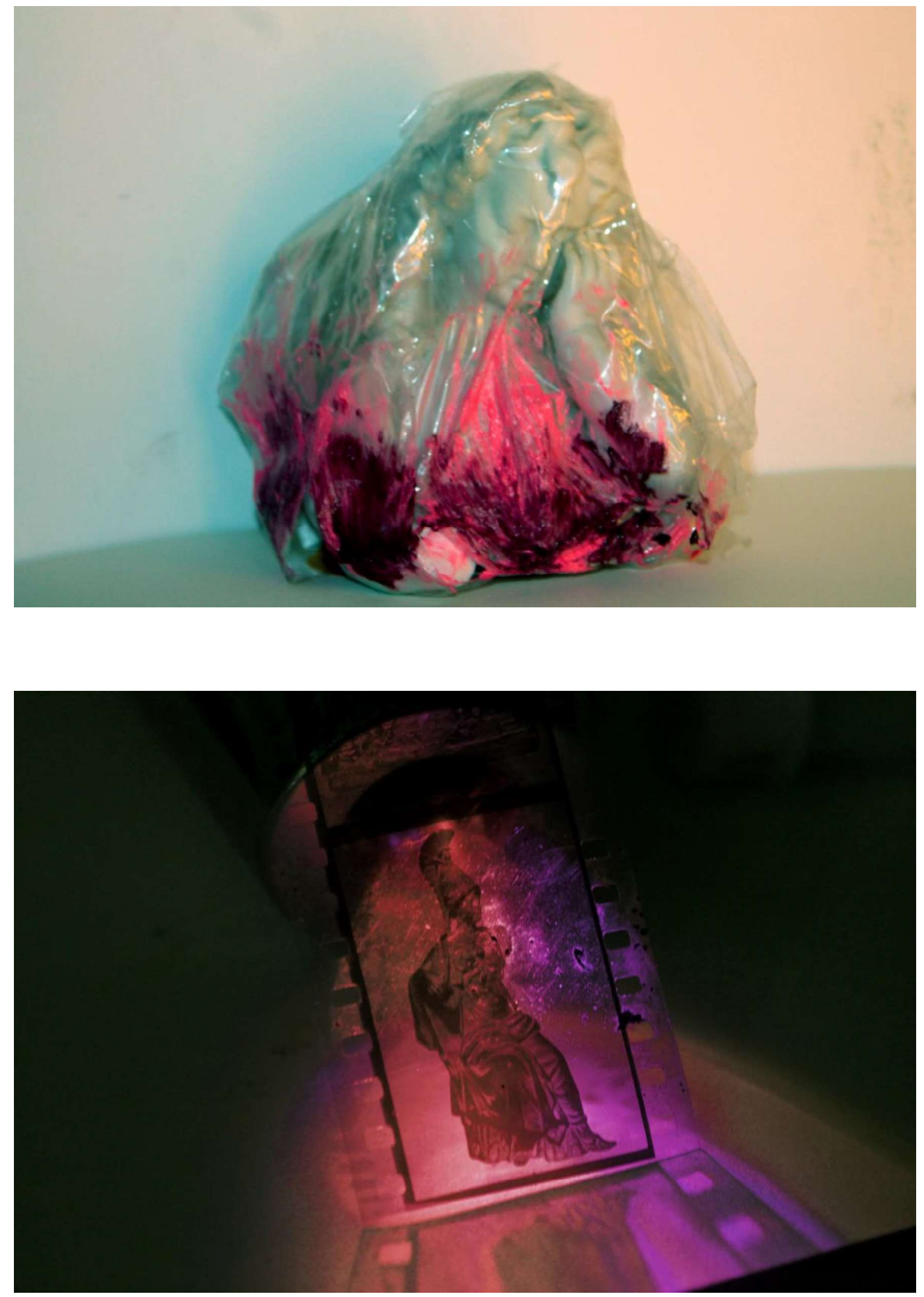

Revista PHILIA | Filosofia, Literatura \& Arte vol. $1, n^{\circ} 2$, outubro de 2019 ISSN 2596-0911 


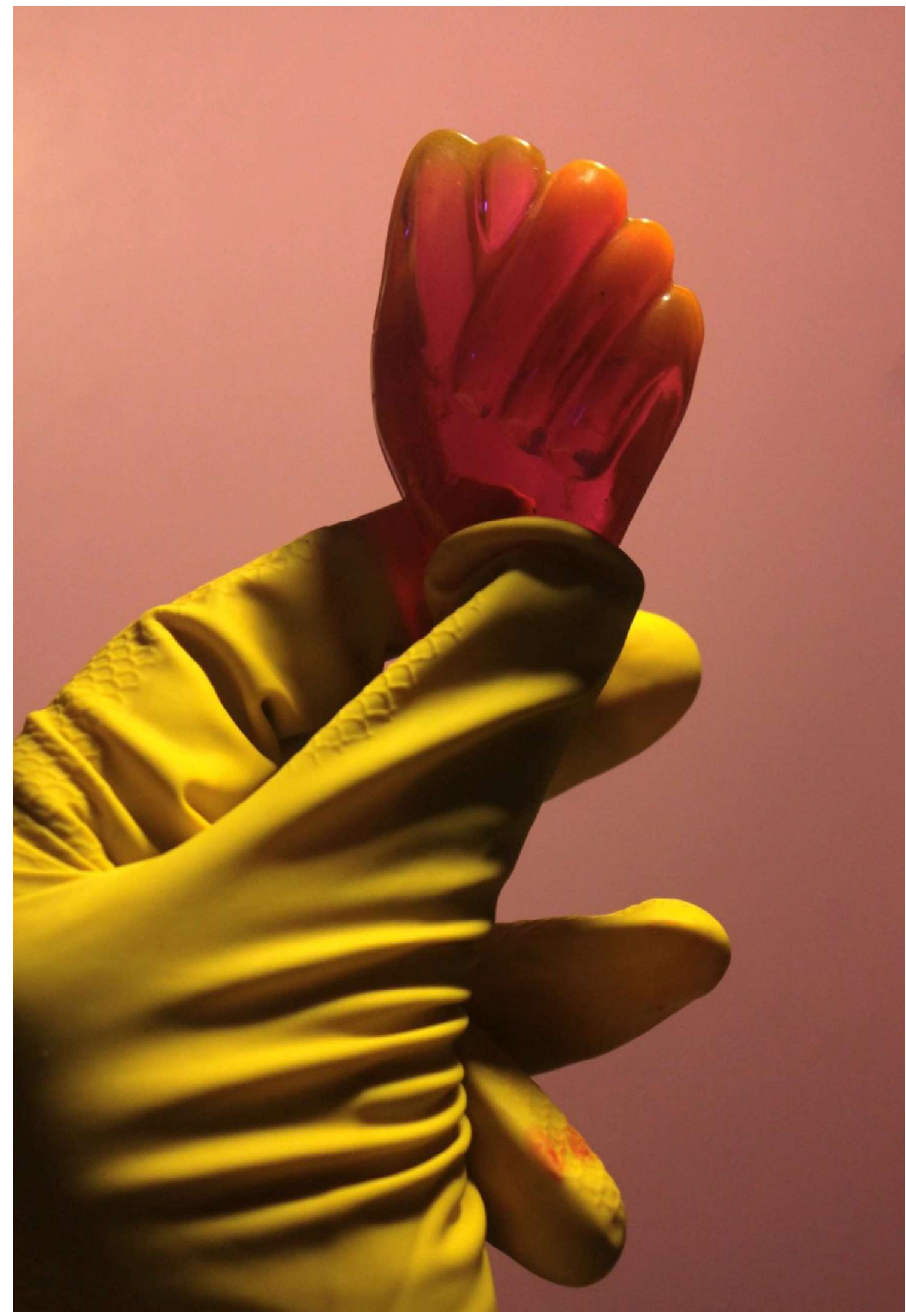




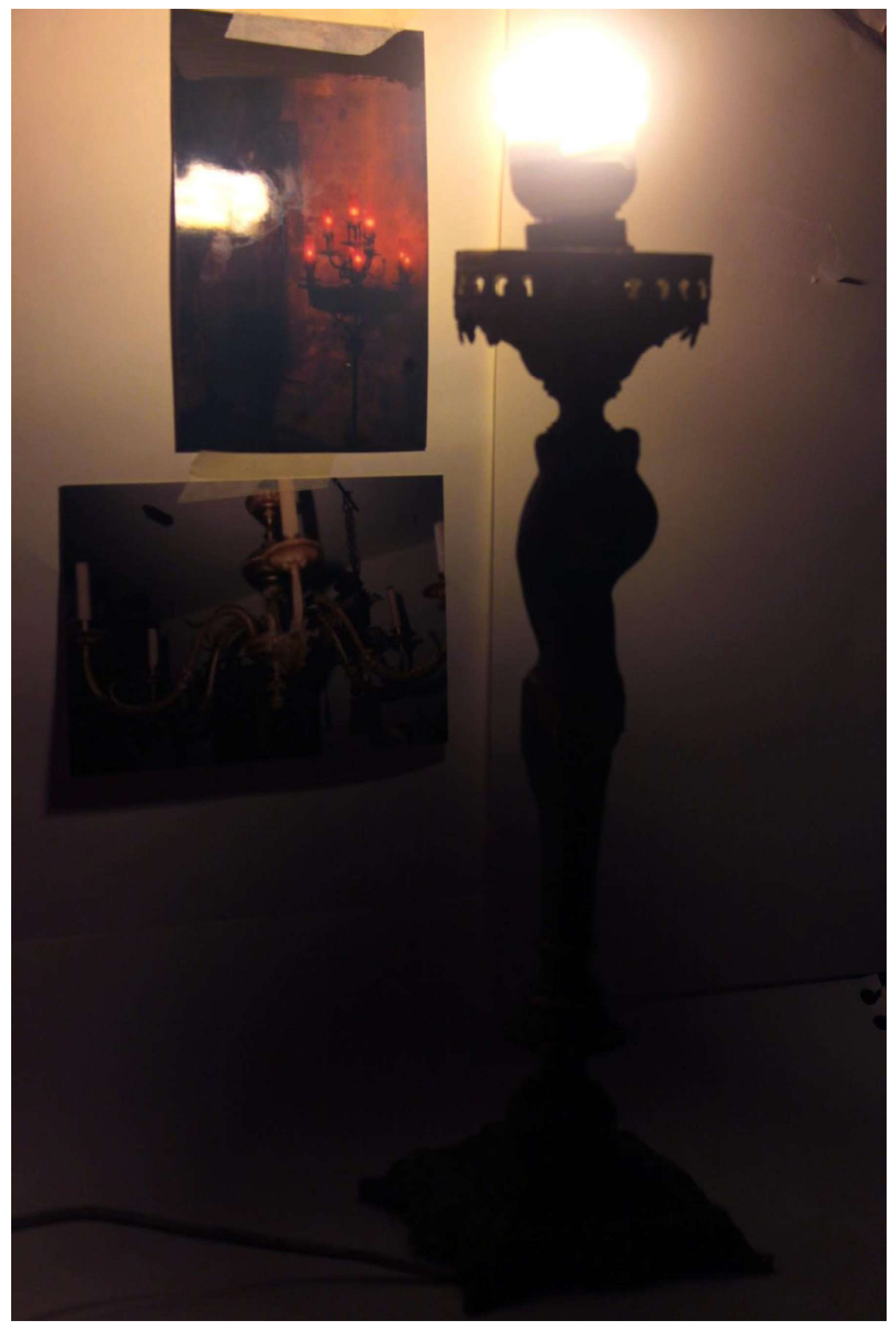




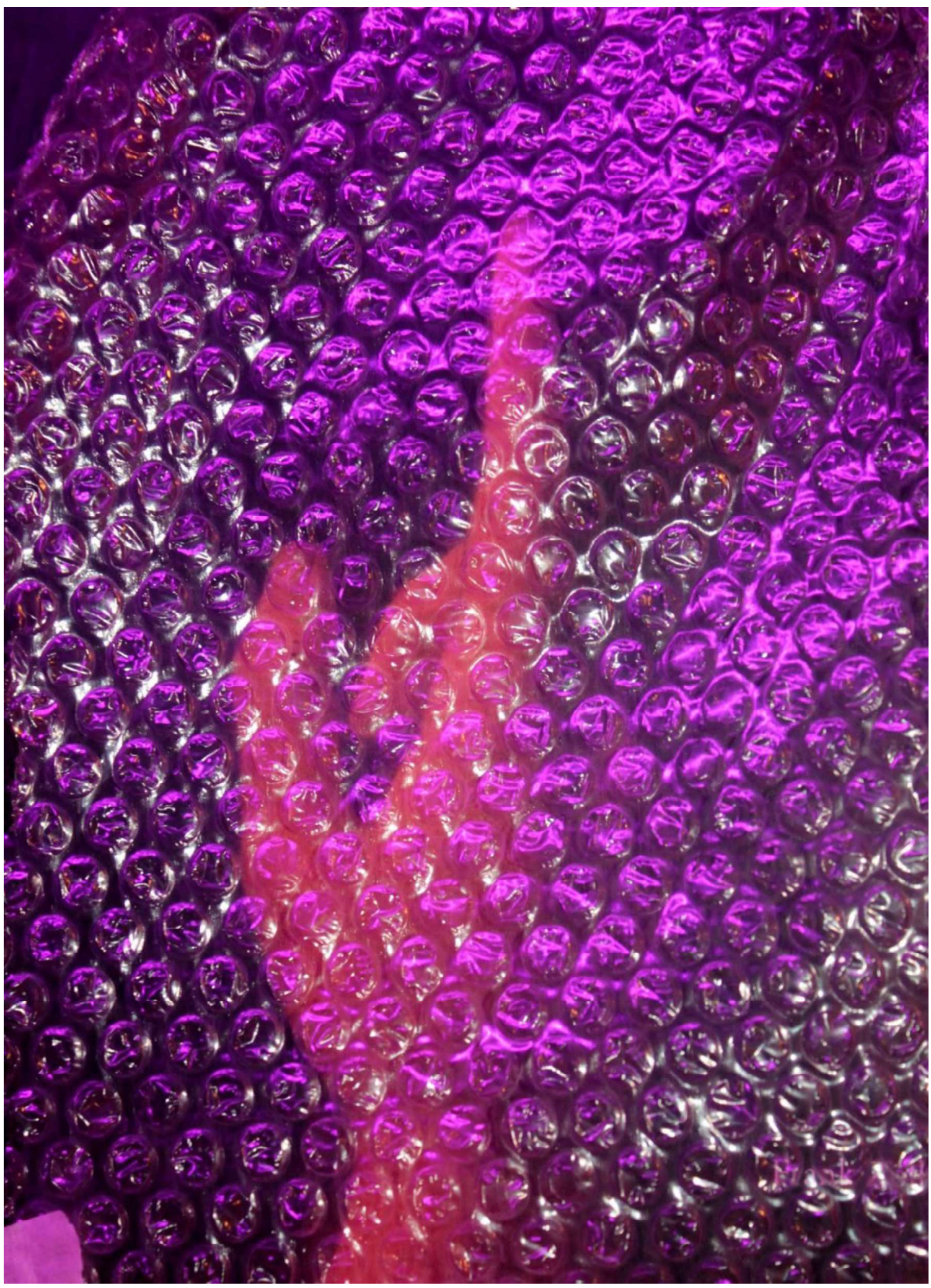


Referência para citação deste ensaio visual

LOPES, L. Elogio ao Mistério: revelações de atelier. Revista PHILIA | Filosofia, Literatura \& Arte, Porto Alegre, volume 1, número 2, p. 627 - 637, outubro de 2019. 